\title{
Clinical Research Training: Scientific Literacy for the Twenty-First Century
}

\author{
Carolyn M. Clancy, MD
}

Agency for Healthcare Research and Quality, Rockville, MD, USA.

$\mathrm{J}$ Gen Intern Med 23(2):219-20

DOI: $10.1007 / \mathrm{s} 11606-007-0485-9$

(c) Society of General Internal Medicine 2007

$\mathrm{C}$ oncerns about the vitality and future of clinical research, including the rapid translation of findings to benefit patients, have been the focus of considerable debate and discussion within and beyond general internal medicine. Challenges to the current enterprise include constraints on research funding, financial pressures on academic medical centers that have diminished institutional support for protected time, and the intrinsic difficulties of balancing family and career responsibilities. The past decade has brought additional training opportunities from the National Institutes of Health, including the recent Clinical Science Translation Awards. However, the impact of specific exposure to research experiences and the content of training have received far less focused attention.

In the February issue of the Journal, Löwe et al. ${ }^{1}$ report on the effectiveness of a 1-year resident training program in clinical research at University Medical Center Heidelberg in 2005. All residents from the Departments of Psychosomatic and General Internal Medicine participated in the program and completed assessments at baseline and 1 year. The same assessments were administered to comparable groups of residents with similar career intentions at two institutions with a similar focus on clinical research. The Clinical Research Methods course consisted of 33 90-minute lectures. The program was considered 'in-service training' and had no extramural support, so participants did not have additional time for research and had no additional time allocated for mentoring experiences. A rigorous evaluation included an assessment of methodological research knowledge, selfassessed research competence, and the number of original publications, reviews or meta-analyses, book articles, and grant proposals at baseline and 1 year. Of note, all residents were expected to pursue careers in clinical research.

Compared with their well-matched peers, residents exposed to the 1-year program demonstrated significantly greater methodological knowledge at 1 year and notably larger increases in self-assessed research competence. Residents participating in the 1-year program were also far more likely than their peers at the two control institutions to be currently writing journal articles. Notwithstanding the relatively small number of residents involved in the study (15 intervention and

Published online January 8, 2008
21 controls), the approach presented here is both thoughtful and rigorous. Not surprisingly, all residents perceived limited time to be an important barrier to research productivity.

The direct relevance to clinical training in the USA may feel a bit distant: a successful career as a clinical researcher clearly requires protected time free of clinical demands and distractions. Moreover, most internal medicine residencies do not include an explicit expectation that graduates will be pursuing independent research, although some residents seek opportunities to engage in research before starting fellowship training. Whether such an approach might stimulate interest of residents in training in a future career in research was not addressed in the thoughtful evaluation.

The salience of this approach to the majority of US residency training programs may be more closely aligned with the core competencies that all practicing physicians will need now and in the future. Those competencies are clearly shaped by several concurrent forces. Advances in biomedical science have long required that practicing physicians commit to a career of life-long learning to keep abreast of new developments in diagnostic and treatment interventions. However, sustained investments in the National Institutes of Health in the 1990s and beyond has resulted in unprecedented developments in molecular biology, genomics, and other area that were not even imagined by current faculty just a few years ago. The practical implication is that clinicians will increasingly confront decisions with patients where two or more options are available; shared decision making will be far more complex. Purchasers and policy makers are demanding that physicians demonstrate performance with respect to quality and value. Increased diffusion of health information technology holds great promise for delivering evidence-based information to the point of care and shortening the oft-discussed delay in incorporating scientific advances in routine practice. The convergence of these forces requires a delivery system that is informationrich, with an urgent need for clinicians with strong skills in information management, interpretation, and application. Although residents are now required to demonstrate learning in the area of systems based practice, the requirements for what might be called scientific literacy have been less clearly articulated.

In short, physicians are increasingly expected to understand and apply methods of evidence-based medicine in patient care. The capacity to understand how evidence is generated, synthesized, and applied to the care of an individual patient with unique characteristics and preference can no longer be considered a special interest but is becoming a required skill set. The current phenomenon of patients asking about products they have seen advertised or read about will grow exponentially. In other words, future physicians will need 
to be "bilingual" in clinical research methods and clinical medicine. The needs for health professionals with these skills are increasingly recognized. A particular strength of the program described here is that the investigators implemented a program that was incorporated into clinical training time, increasing the potential for the training to influence how residents consider the strength of clinical evidence in their daily work.

Students and residents today are exposed to evidence-based medicine in intermittent and variable doses. SGIM members who have led the way in educational innovations are well positioned to consider the course reported here as a template for preparing today's learners for a very different future. Together with their research colleagues, they can anticipate the health care dilemmas of the future and identify the core components of scientific literacy for the twenty-first century physicians.

Corresponding Author: Carolyn M. Clancy, MD; Agency for Healthcare Research and Quality, John M Eisenberg Building, 540 Gaither Road, Rockville, MD 20850, USA (e-mail: carolyn.clancy@ ahrq.hhs.gov).

\section{REFERENCE}

1. Löwe B, Hartmann M, Wild B, Nikendei C, Kroenke $K$, Niehoff $\mathbf{D}$, Henningsen P, Zipfel S, MD, Herzog W. Effectiveness of a 1-year resident training program in clinical research: A controlled before-and-after study. J Gen Intern Med. DOI 10.1007/s11606-007-0397-8. 